\title{
Annotation
}

\section{Dimensional Communalities of the Deciduous Teeth}

\author{
Stanley M. Garn, Patricia E. Cole, and Robert L. Wainright \\ Center for Human Growth and Development, University of Michigan, Ann Arbor Michigan \\ 48109, USA
}

\section{J Dent Res 56(10):1208 October 1977 .}

Although there have been numerous studies of the extent to which the crown dimensions of the permanent teeth are correlated (MOORREEs and REED, Arch Oral Biol 9:685, 1964; GARN, Lewis and Kerewsky, $J$ Dent Res 44:350, 1965) comparable information on deciduous tooth dimensional communalities is meagre. Moreover, it is not known whether the crown dimensions of the deciduous teeth show different patterns of correspondence from those exhibited by the permanent teeth of the same individuals.

Turning, then, to optical-scanner (OPTOCOM) mesiodistal crown measurements of 204 boys and girls from Southeastern Michigan (VAN DER Linden et al, J Dent Res 51: 1100, 1972; Garn et al, J Dent Res 56:697, 1977) complete intercorrelation matrices were calculated for 20 deciduous teeth, for boys and girls respectively, and compared with correlations for 20 successional (permanent) teeth from the same individuals. Since correlations involving the right and left sides were not systematically different, the sides were pooled to simplify the presentation. However, crown-size correlations for boys and girls were analyzed separately, since a systematic sex difference emerged. Moreover, attention was given to individual teeth, to morphological classes, and to distance between teeth within each arch, in order to test for a "distance" effect.

As shown in the table, deciduous tooth intercorrelations are slightly higher for bovs in the sample $(R=0.54)$ than for girls $(R=$ 0.45 ) a trend significant by sign test for 20 paired correlations $\left(\chi^{2}=7.2\right)$. Within the arches, the highest correlations are for teeth of the same morphological class $(r=0.64)$, then those for adjacent teeth $(r=0.56)$ and then for teeth more widely separated. Mean values for $r$ are $0.43,0.45$ and 0.46 for 1,2 and 3 intervening teeth, respectively. Finally, the mean value of $r$ for 20 deciduous teeth is slightly higher than the mean mesiodistal crown-

This study was supported in part by Grant DE03610 from the National Institutes of Health.

Received for publication April 5, 1977.

Accepted for publication April 28, 1977.
TABLE

INTRA-ARCh Dimensional SimilartTiEs IN THE DECIDUOUS DENTITION*

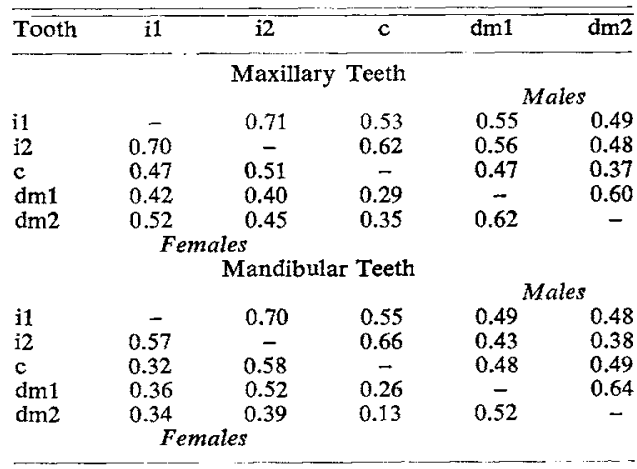

* Data for 4,080 pairs of teeth for 204 individuals. Correlations for males are to the right of the diagonal and females are to the left of the diagonal.

size intercorrelations for 20 successional (permanent) teeth for the same individuals. As compared with mean deciduous tooth correlations of 0.54 and 0.45 for boys and girls respectively, permanent tooth intercorrelations were 0.44 for boys and 0.39 for girls, here restricting the comparison to I1 through P2.

These findings show that deciduous tooth crown-size communalities are not lower than those for 20 successional teeth from the same individuals and that adjacent deciduous teeth and especially teeth of the same morphological class exhibit the highest dimensional correspondences. This evidence and the evidence for dimensional correspondences between deciduous and permanent teeth from the same individual (LYSELL, Sartryck ur Odontologisk Tidskrift 65:571, 1957; Lysell, Acta Odontol Scand 18: 1, 1960; Garn, Cole, and Wainrigh'r, J Dent res $56: 1214,1977$ ) suggest that the same control mechanisms determine crown dimensions of both deciduous and permanent teeth, including those forming in prenatal as well as postnatal time. 